\title{
Neuropathologic description of CHCHD10 mutated amyotrophic lateral sclerosis
}

\author{
Julia L. Keith, MD, Emily Swinkin, MD, Andrew Gao, MD, Samira Alminawi, MLT, Ming Zhang, PhD, \\ Philip McGoldrick, PhD, Paul McKeever, PhD, Janice Robertson, PhD, Ekaterina Rogaeva, PhD, and \\ Lorne Zinman, MD
}

Neurol Genet 2020;6:e394. doi:10.1212/NXG.0000000000000394

\begin{abstract}
\section{Objective}

To present the postmortem neuropathologic report of a patient with a CHCHD10 mutation exhibiting an amyotrophic lateral sclerosis (ALS) clinical phenotype.
\end{abstract}

\section{Methods}

A 54-year-old man without significant medical history or family history presented with arm weakness, slowly progressed over 19 years to meet the El Escorial criteria for clinically probable ALS with bulbar and respiratory involvement, and was found to have a CHCHD10 p.R15L mutation. Postmortem neuropathologic examination took place including immunohistochemical staining with $\mathrm{CHCHD} 10$, and double immunofluorescence combining $\mathrm{CHCHD} 10$ with TDP43 and neurofilament was performed and the results were compared with normal controls and sporadic ALS cases.

\section{Results}

Postmortem examination of the $\mathrm{CHCHD} 10$ mutation carrier showed severe loss of hypoglossal and anterior horn motor neurons, mild corticospinal tract degeneration, and a relative lack of TDP43 immunopathology. CHCHD10 immunohistochemistry for the 3 controls and the 5 sporadic ALS cases showed strong neuronal cytoplasmic and axonal labeling, with the $\mathrm{CHCHD} 10$ mutation carrier also having numerous $\mathrm{CHCHD} 10$ aggregates within their anterior horns. These aggregates may be related to the $\mathrm{CHCHD} 10$ aggregates recently described to cause mitochondrial degeneration and disease in a tissue-selective toxic gain-of-function fashion in a CHCHD10 knock-in mouse model. The CHCHD10 aggregates did not colocalize with TDP43 and were predominantly extracellular on double immunofluorescence labeling with neurofilament.

\section{Conclusions}

The neuropathology of CHCHD10 mutated ALS includes predominantly lower motor neuron degeneration, absent TDP43 immunopathology, and aggregates of predominantly extracellular CHCHD10, which do not contain TDP43.

\footnotetext{
From the Laboratory Medicine and Molecular Diagnostics (J.L.K., A.G., S.A.), Division of Anatomical Pathology, Sunnybrook Health Sciences Centre, University of Toronto; Department of Medicine (E.S., L.Z.), Division of Neurology, Sunnybrook Health Sciences Centre, University of Toronto, Ontario, Canada; School of Medicine and Institute for Advanced Study (M.Z.), Tongji University, Shanghai, China; and Tanz Centre for Research in Neurodegenerative Diseases (M.Z., P. McGoldrick, P. McKeever, J.R., E.R.), University of Toronto, Ontario, Canada. 


\section{Glossary}

ALS = amyotrophic lateral sclerosis; FTD = frontotemporal dementia; FTDALS2 = frontotemporal dementia and $/$ or amyotrophic lateral sclerosis-2; NF = neurofilament.

Heterozygous mutations clustered in exon 2 of coiled-coilhelix-coiled-coil-helix domain-containing 10 ( $\mathrm{CHCHD10})$ have recently been described in clinically heterogeneous neurodegenerative phenotypes including amyotrophic lateral sclerosis (ALS) $)^{1}$ (figure 1 ). The discovery of mutations in this gene encoding the mitochondrial $\mathrm{CHCHD} 10$ protein has lent support to the long-suspected role of mitochondrial dysfunction in the pathogenesis of ALS, but the exact mechanism is uncertain. Recently, we reported that the ALS-causing p.R15L mutation destabilizes the CHCHD10 protein in fibroblasts derived from the carrier, leading to impaired cellular respiration and an increase in the steady-state level of its paralogue $\mathrm{CHCHD} 2$ protein. $^{2}$ The current report is a description of the observed neuropathology from a patient harboring a loss-of-function p.R15L CHCHD10 mutation.

\section{Methods}

The CHCHD10 p.R15L mutation (rs730880030) in patient with ALS \#8807 (free from mutations in C9orf72, SOD1, GRN, FUS, MATR3, CHCHD2, and TARDBP) was previously reported as part of a Canadian cohort with neurodegenerative disorders, ${ }^{3}$ but without clinical details. This patient has now been investigated on a genome-wide exome array tailored to study neurodegenerative diseases (NeuroX; Illumina, San Diego, $\mathrm{CA}^{4}$ ) for potentially damaging rare variants with a minor allele frequency $<0.1 \%$. Among the detected 63 rare variants, none are known to affect genes implicated in neurodegenerative diseases (table e-1, links.lww.com/NXG/A219).

The patient recently died at age 72 years, he had consented to autopsy, and on his death, a thorough review of his clinical records, and within 6 hours of his death, a postmortem examination limited to the brain and spinal cord were performed. The left cerebral hemisphere, hemi-brainstem, and cerebellum and 3 segments of the spinal cord were fixed in $10 \%$ formalin, whereas the remainder of the CNS was frozen. After fixation, the left cerebral hemisphere was sectioned coronally, the hemibrainstem and spinal cord segments were sectioned axially, the hemi-cerebellum was sectioned sagittally, and a standard neuropathology blocking protocol for ALS was followed. The tissue blocks were cut into 4- $\mu \mathrm{m}$ thick sections, mounted on glass slides, and stained with hematoxylin and eosin/luxol fast blue and immunohistochemistry for TDP43, p62, tau (AT8), beta-amyloid, fused in sarcoma, alpha-synuclein, $\mathrm{CHCHD10}$, and $\mathrm{CHCHD} 2$ (detailed immunohistochemical methods are provided in table 1). Pertinent microscopic slides were scanned using an Aperio scanner, and digitized photomicrographs were taken.

Figure 1 Gene structure of $\mathrm{CHCHD} 10$

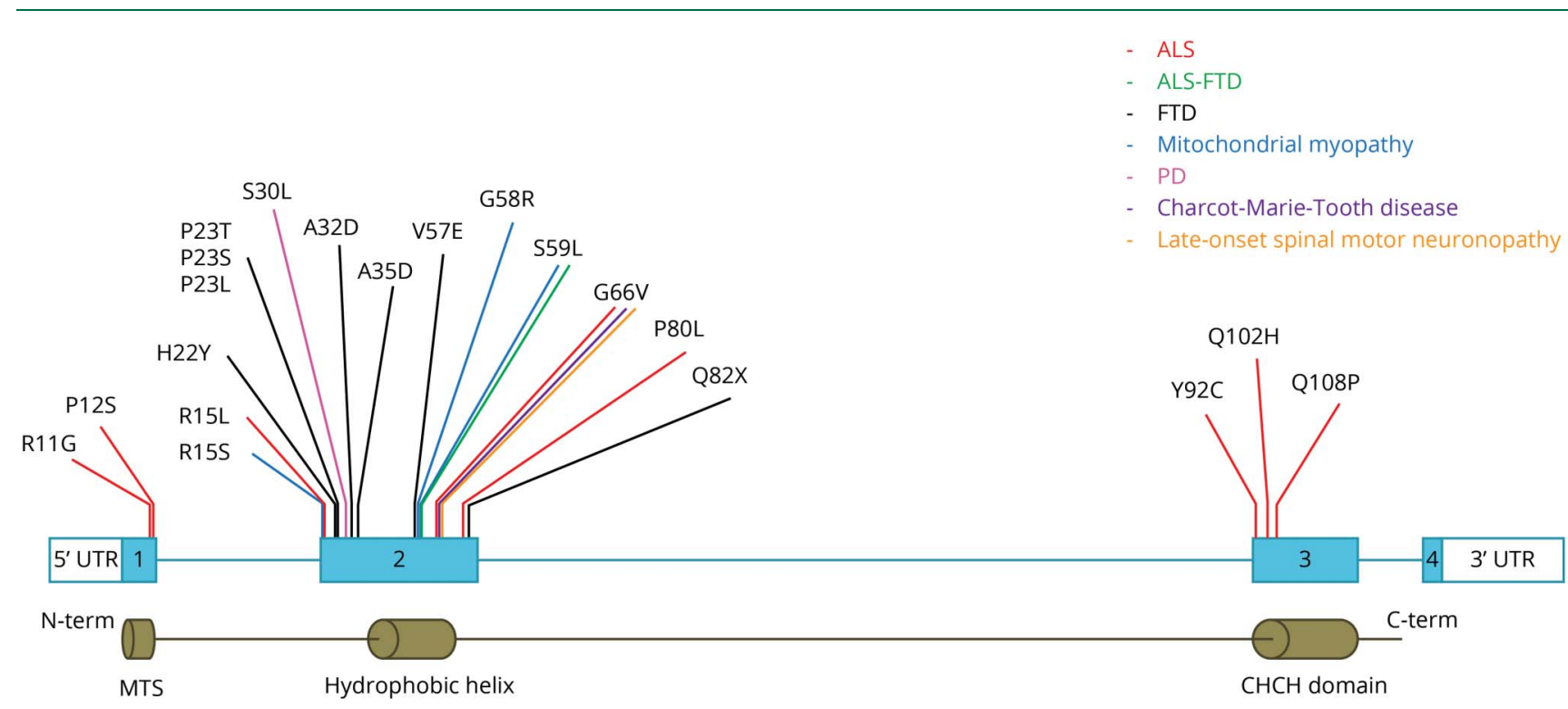

The upper diagram is the gene structure of $\mathrm{CHCHD10}$ with 4 coding exons. The lower diagram is the CHCHD10 protein structure (142 amino acid), which includes an MTS (amino acids 1-16), a hydrophobic domain (amino acids 43-68), and a CHCH domain (amino acids 102-133). Mutations that have been described are shown above of the gene structure, and the colored lines indicate the diagnosis of the patient(s) with the reported mutation: ALS (red), ALS-FTD (green), FTD (black), mitochondrial myopathy (blue), Parkinson Disease (pink), Charcot-Marie-Tooth disease (purple), and late-onset spinal motor neuronopathy (orange). ALS = amyotrophic lateral sclerosis; FTD = frontotemporal dementia; MTS = mitochondrial localization signal. 
Table 1 Immunohistochemical methods used

\begin{tabular}{|c|c|c|c|c|c|c|c|}
\hline Antibody & Clone & Vendor & Dilution & Heat retrieval & $\begin{array}{l}\text { Antibody } \\
\text { incubation time }\end{array}$ & Detection system & Instrument \\
\hline TDP43 & Polyclonal & Cedarlane & $1 / 2,000$ & $\begin{array}{l}\text { High } p H, 96^{\circ} \mathrm{C}, 30 \\
\min \end{array}$ & $15 \min$ & $\begin{array}{l}\text { EnVision Flex Dako } \\
\text { detection }\end{array}$ & Omnis \\
\hline Tau (AT8) & pSpS1991202 & $\begin{array}{l}\text { Thermo } \\
\text { Fisher }\end{array}$ & $1 / 200$ & $\begin{array}{l}\text { Low } \mathrm{pH}, 118^{\circ} \mathrm{C}, 2 \\
\min \end{array}$ & $60 \mathrm{~min}$ & Mach 4 & MANUAL \\
\hline Beta-amyloid & $6 F / 3 D$ & Dako & $1 / 200$ & $\begin{array}{l}\text { Low } \mathrm{pH}, 118^{\circ} \mathrm{C}, 2 \\
\min \end{array}$ & $60 \mathrm{~min}$ & Mach 4 & MANUAL \\
\hline FUS & Polyclonal & Sigma & $1 / 100$ & $\begin{array}{l}\text { Low } \mathrm{pH}, 118^{\circ} \mathrm{C}, 2 \\
\min \end{array}$ & $60 \mathrm{~min}$ & Mach 4 & MANUAL \\
\hline $\begin{array}{l}\text { Alpha- } \\
\text { synuclein }\end{array}$ & LB509 & Invitrogen & $1 / 500$ & $\begin{array}{l}\text { Low } \mathrm{pH}, 96^{\circ} \mathrm{C}, 30 \\
\min \end{array}$ & $20 \min$ & $\begin{array}{l}\text { EnVision Flex Dako } \\
\text { detection }\end{array}$ & Omnis \\
\hline P62 & 3/p62lck & $\mathrm{BD}$ & $1 / 200$ & $\begin{array}{l}\text { High } \mathrm{pH}, 96^{\circ} \mathrm{C}, 30 \\
\min \end{array}$ & $30 \mathrm{~min}$ & $\begin{array}{l}\text { EnVision Flex Dako } \\
\text { detection }\end{array}$ & Omnis \\
\hline CHCHD2 & Polyclonal & Novus & $1 / 200$ & $\mathrm{CC} 1,64 \mathrm{~min}$ & $40 \mathrm{~min}$ & OptiView & $\begin{array}{l}\text { BenchMark } \\
\text { Ultra }\end{array}$ \\
\hline CHCHD10 & Polyclonal & Novus & $1 / 200$ & $\mathrm{CC} 1,64 \mathrm{~min}$ & $40 \mathrm{~min}$ & OptiView & $\begin{array}{l}\text { BenchMark } \\
\text { Ultra }\end{array}$ \\
\hline
\end{tabular}

In attempts to understand the immunohistochemical staining patterns of $\mathrm{CHCHD} 10$ and $\mathrm{CHCHD} 2$ in our case, sections from the cervical spinal cord and frontal cortex from 8 other autopsy cases were also stained with these antibodies, including 5 cases of pathologically confirmed ALS and 3 normal controls (additional information is provided in table e-2, links. lww.com/NXG/A220). All the CHCHD10 and CHCHD2 immunostained slides were reviewed blindly and independently by 2 neuropathology assessors (J.L.K. and A.G.).

Sections from the CHCHD10 p.R15L mutation case, 1 sporadic ALS case, and 1 normal control were also examined with immunofluorescence. Formalin-fixed, paraffin-embedded sections through the cervical spinal cord were deparaffinized by placing on a $60^{\circ} \mathrm{C}$ heat block for 20 minutes and then in xylene ( $3 \times 5$ minutes). Rehydration was then performed with sequential graded ethanol washes (100\%, 95\%, 75\%, and 50\% wt/ vol) before pure water. Heat-induced antigen demasking was completed using Tris-EDTA buffer (10 mM Trizma base, $1 \mathrm{mM}$ EDTA, $0.1 \%$ Tween $20, \mathrm{pH} 9.0$ ) at $110^{\circ} \mathrm{C}$ for 15 minutes in a pressure cooker. Blocking was performed with $10 \%$ donkey serum (EMD Millipore, Ontario, Canada) and 0.3\% TX-100 in tris buffered saline for 1 hour at ambient temperature. Primary antibody incubation was performed overnight at $4^{\circ} \mathrm{C}$ with antirat phosphoTDP43 (Ser409/410) antibody, clone 1D3 (1: 1000; Millipore-Sigma, Ontario, Canada, cat\# MABN14), and anti-rabbit CHCHD10 (1:200; Novus Biologicals, Littleton, CO, cat\# NBP1-91169) diluted in DAKO Antibody Diluent (S0809). Processes were labeled separately by pooling antimouse nonphosphorylated anti-neurofilament (NF) $\mathrm{H}$ (BioLegend, San Diego, CA, cat\# SMI32) and anti-NFH (NF$\mathrm{H}$; BioLegend, cat\# SMI31) (both 1:500 wt/vol) and paired with anti-rabbit CHCHD10 (1:200; Novus Biologicals, cat\# NBP1-91169) diluted in DAKO Antibody Diluent. After $3 \times 20$ minute washes in tris buffered saline $+0.1 \%$ Tween 20 (tris buffered saline tween), secondary incubation was performed for 1 hour at ambient temperature with either donkey $\alpha$-rat 488 or donkey $\alpha$-mouse 488 paired with donkey $\alpha$-rabbit 594 Alexa Fluor secondary antibodies (Invitrogen, Carlsbad, CA; 1:500) diluted in DAKO Antibody Diluent. Slides were washed $3 \times 20$ minutes in tris buffered saline tween before mounting with ProLong Gold Antifade reagent with 4',6-diamidino-2phenylindole [DAPI] (P36931; Life Technologies, Carlsbad, CA). Photomicrographs of the double IF labeling were captured on a Leica DMI6000B microscope with the Volocity Acquisition Suite (v6.3; PerkinElmer, Waltham, MA).

\section{Standard protocol approvals, registrations, and patient consents}

This study was approved by the Research Ethics Board at Sunnybrook Health Sciences Centre.

\section{Data availability}

Access to anonymized data related to the current study will be available from the corresponding author (J.L.K.) on request.

\section{Results}

The CHCHD10 p.R15L mutation carrier was Caucasian, without a family history of neurologic disease (mother died at age 77 years of a myocardial infarction, father died suddenly at age 65 years, and 2 siblings are both healthy in their $60 \mathrm{~s}$ ). The patient began manifesting neurologic symptoms at age 54 years with right arm weakness. The weakness involved both arms over the next 2 years and was worse proximally. On examination, the patient initially had exclusively lower motor neuron signs, muscle wasting, and fasciculations in the arms. By age 61 years, the patient developed spastic dysarthria with tongue and perioral fasciculations and lower extremity hyperreflexia with 
fasciculations and intact power. EMG revealed active and chronic denervation in all segments. An MRI of the cervical spine revealed degenerative changes in the cervical spine without canal or foraminal narrowing to account for the symptoms, and bloodwork was normal including $\mathrm{CBC}$, electrolytes, liver enzymes, ESR, CRP, ANA, RF, serum protein electrophoresis, anti-GM1 antibodies, and West Nile virus serology. Given the presence of lower motor neuron signs in the bulbar, cervical, thoracic, and lumbosacral segments in addition to upper motor neuron signs in the bulbar and lumbosacral segments, the presentation was consistent with clinically probable ALS based on contemporary El Escorial criteria, ${ }^{5}$ and the patient was started on Riluzole (Rilutek, ATC Code N07X X02). By age 62 years, the patient had dyspnea requiring overnight BiPAP, and by age 69 years, they required BiPAP for most of the day and had upper limb flaccid weakness ( $1 / 5$ proximally and $4-/ 5$ distally) but retained the ability to walk with mild $(4+/ 5)$ proximal lower limb weakness. Bulbar and respiratory weakness progressed, and the patient obtained medical assistance in dying at age 72 years. Throughout their disease course, the patient never demonstrated cognitive, affective, or personality changes, although formal neuropsychological testing was not performed.

On neuropathologic macroscopic examination, the fresh brain weight was $1,560 \mathrm{~g}$, the cerebral gyri were a normal caliber externally, and coronal sections through the left hemisphere showed no abnormalities of the cerebral cortex, white matter, and mesial temporal or deep gray structures. Axial sections through the brainstem were unremarkable. The anterior spinal nerve roots were thin and pale, and axial sections through the spinal cord appeared otherwise normal.

On microscopic examination, there were findings typical of ALS within the spinal cord and brainstem as shown in figure 2. At all levels of the spinal cord, there was mild degeneration of the lateral corticospinal tract (figure $2 \mathrm{~A}$ ). There was severe loss of motor neurons and gliosis within the anterior horns (figure $2 \mathrm{~B}$ ), more pronounced in the cervical levels, with rare cytoplasmic eosinophilic p62 immunopositive inclusions in remaining motor neurons, the morphology of which ranged from ill-defined faintly eosinophilic structures to large, densely eosinophilic round structures reminiscent of corpora amylacea. There were no neuronal inclusions present that immunolabeled with TDP43 (figure 2C), fused in sarcoma, tau (AT8), or alpha-synuclein. No Bunina bodies were seen. There was also severe neuronal loss and gliosis within the hypoglossal nucleus (figure 2D) without p62 or TDP43 immunopositive inclusions.

Other findings in the brainstem included scattered long thin p62 immunopositive neurites throughout the medullary tegmentum and olivary nuclei, a normal population of pigmented neurons within the substantia nigra without Lewy bodies, rare nigral neurons contained filamentous cytoplasmic TDP43 immunopositive inclusions, and the remainder of the brainstem was unremarkable including the motor nuclei of cranial nerve V, VI, and VII.
Cortical sections showed a relatively normal complement of Betz motor neurons (figure 2E) without p62/TDP43 immunopositive inclusions within the primary motor cortex (figure 2F). There was no significant atrophy of the frontal or temporal cortex. Only rare p62 immunopositive long thin neurites and neuronal cytoplasmic inclusions were seen in the superficial layers of the frontal cortex. No cortical amyloid plaques or neurofibrillary tangles were present. The mesial temporal structures showed mild gliosis of the endplate and CA1, but there was no mesial temporal sclerosis and no p62/ TDP43-positive inclusions were present. Sections treated with tau (AT8) immunohistochemistry highlighted (+) neurofibrillary tangles within CA1 and $(++)$ neurofibrillary tangles within the superficial layers of the entorhinal cortex, corresponding to mild primary age-related tauopathy. There was no alpha-synuclein pathology. The deep gray nuclei, cerebellar cortex, and dentate nuclei appeared normal.

The results of $\mathrm{CHCHD} 2$ and $\mathrm{CHCHD} 10$ immunohistochemistry are shown in figure 3 and figure e-1 (links.lww. com/NXG/A218). The CHCHD2 immunolabeling was comparable between the CHCHD10 mutated ALS case, normal controls, and sporadic ALS; all showed strong neuronal, glial, and endothelial cytoplasmic labeling in gray and white matter within the spinal cord (figure $3, \mathrm{~A}-\mathrm{C}$ ) and cerebral cortex. CHCHD10 immunohistochemistry was comparable for the normal controls and sporadic ALS, all showing strong neuronal cytoplasmic and axonal labeling (figure 3D). The CHCHD10 mutated ALS case showed a different pattern of $\mathrm{CHCHD} 10$ labeling; in addition to the strong neuronal cytoplasmic and axonal staining seen in the other cases, there were also numerous aggregates of $\mathrm{CHCHD} 10$ within the anterior horns, slightly more abundant at cervical levels (figure 3, E-G, figure e-1, A-C, links.lww.com/NXG/A218). These aggregates had a dense central core and a surrounding halo of CHCHD10 immunopositivity (figure 3, H and I), and they did not contain $\mathrm{CHCHD} 2$. Also present were rare corkscrew-shaped CHCHD10 immunopositive inclusions within all levels of the anterior horn (figure $3, \mathrm{~F}$ and $\mathrm{J}$ ). The frontal cortex of the CHCHD10 mutated case showed predominantly strong neuronal cytoplasmic and axonal labeling with $\mathrm{CHCHD} 10$, but $\mathrm{CHCHD} 10$ aggregates and corkscrewshaped inclusions were also present focally in the superficial cortical layers (figure e-1, D-F).

The results of double immunofluorescence immunolabeling for $\mathrm{CHCHD} 10$ and TDP43 and for CHCHD10 and NF are shown in figure 4. In the sporadic ALS case, TDP43-positive filamentous neuronal cytoplasmic inclusions were seen within anterior horn motor neurons (figure 4A, green). There was faint neuronal cytoplasmic expression of $\mathrm{CHCHD} 10$ within all motor neurons (figure 4A, red), but the TDP43-positive inclusions did not colabel with CHCHD10. In comparison, the CHCHD10 mutated ALS case contained many corkscrewshaped CHCHD10-positive structures within the anterior horn, and these CHCHD10 aggregates did not colabel with TDP43 (figure 4B). Double immunolabeling for CHCHD10 
Figure 2 Predominantly lower motor neuron degeneration within the spinal cord and brainstem of CHCHD10 mutated amyotrophic lateral sclerosis case

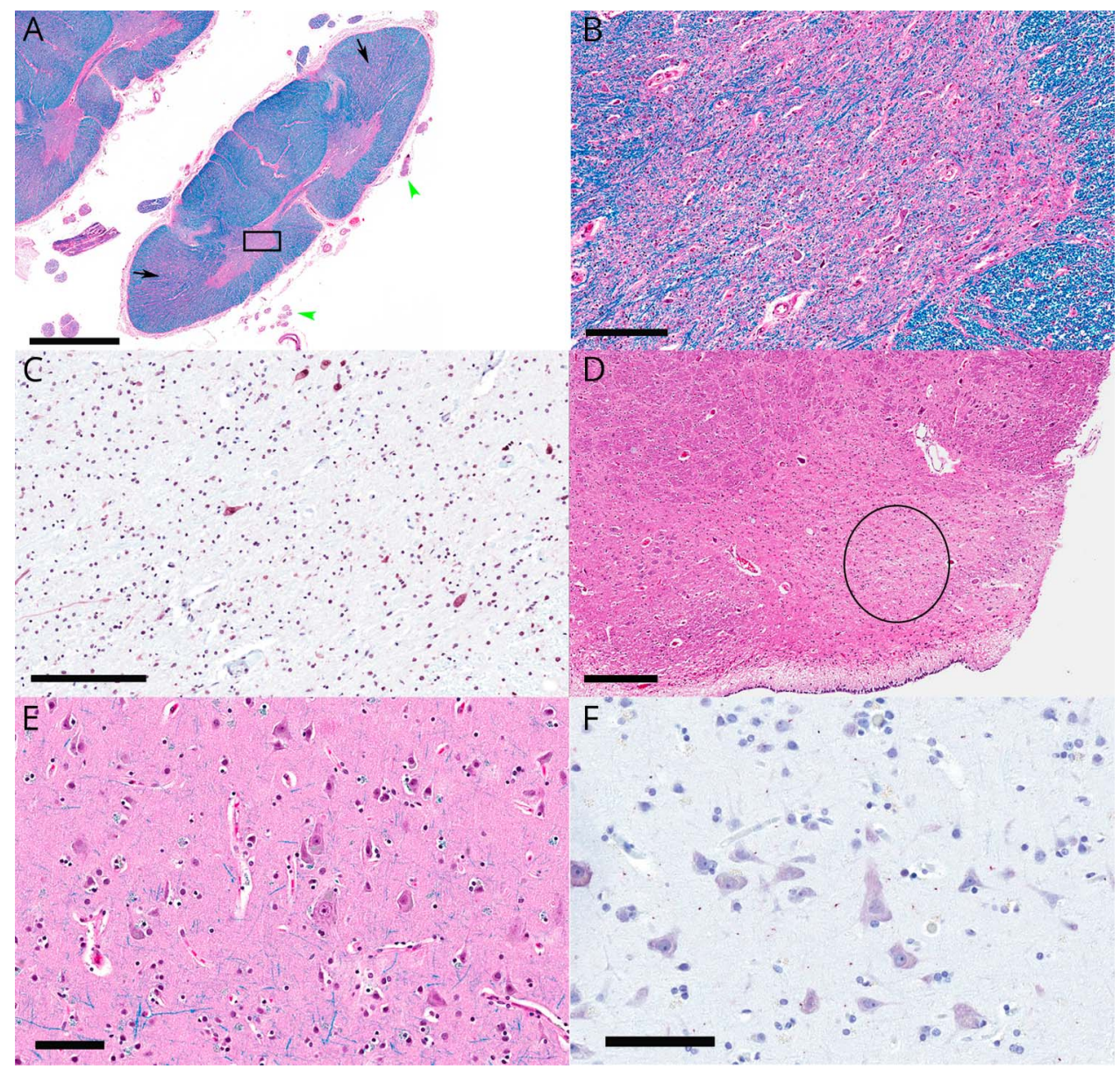

(A) Hematoxylin and eosin (H\&E)/LFBstained section of the cervical spinal cord showing mild bilateral degeneration of the lateral corticospinal tracts (black arrows) and thin and pale anterior spinal nerve roots on myelin staining (green arrowheads) in comparison to the posterior spinal nerve roots. (B and C) H\&E/LFB and TDP43 staining of the anterior horn of the cervical spinal cord (area depicted in black box in figure $1 \mathrm{~A}$ ) showing severe neuronal loss and gliosis without TDP43 immunopositive inclusions in remaining motor neurons. (D) H\&E-stained section of the medullary tegmentum showing severe neuronal loss and gliosis within the hypoglossal nucleus (black ellipse). ( $E$ and F) Normal population and morphology of Betz neurons in the motor cortex, which do not contain TDP43-positive inclusions. Scale bar $=3 \mathrm{~mm}(A), 200 \mu \mathrm{m}(B$ and $C)$, $300 \mu \mathrm{m}(\mathrm{D})$, and $100 \mu \mathrm{m}$ ( $\mathrm{E}$ and F). LFB $=$ luxol fast blue. and NF in the normal control case confirmed cytoplasmic immunolabeling for $\mathrm{CHCHD} 10$ within the anterior horn motor neurons and also showed many small, CHCHD10positive neurites in the background (figure $4 \mathrm{C}, \mathrm{CHCHD} 10$ in red and NF in green). In the anterior horns of the $\mathrm{CHCHD} 10$ mutated ALS case, the vast majority of $\mathrm{CHCHD} 10$ aggregates appeared to be corkscrew shaped and extracellular, as they had no associated NF immunolabeling (figure 4, D, G, and $\mathrm{H}$ ). However, very rare $\mathrm{CHCHD} 10$ neuronal cytoplasmic inclusions were also seen (figure 4D), and rare examples of $\mathrm{CHCHD} 10$ labeling were seen surrounded by a thin rim of $\mathrm{NF}$, which suggests that some CHCHD10 inclusions may be within neuronal cell processes.

\section{Discussion}

The CHCHD10 protein is in the mitochondrial intermembrane space, enriched in mitochondrial cristae junctions. ${ }^{1}$ The exact function of the $\mathrm{CHCHD} 10$ protein continues to be elucidated, but it may alter fragmentation of mitochondria, increase instability of mitochondrial DNA, and decrease mitochondrial complex-IV activity. ${ }^{1,6} \mathrm{CHCHD} 10$ forms part of the multiprotein complex MICOS, which plays a vital role in the formation and maintenance of cristae structure. ${ }^{7}$ A recent study ${ }^{8}$ demonstrated that $\mathrm{CHCHD} 10$ is a regulator of mitochondrial respiration and can contribute to transcriptional repression of oxygen-responsive element containing genes, and some genetic CHCHD10 variants (G66V and P80L) are impaired in these activities.

Patients with $\mathrm{CHCHD} 10$ mutations have a broad clinical phenotypic range (figure 1), including ALS/frontotemporal dementia (FTD), ${ }^{1,9}$ ALS, ${ }^{3,10,11}$ FTD $^{3}$ mitochondrial myopathy, ${ }^{6,12}$ ataxia, ${ }^{13}$ parkinsonism, ${ }^{14}$ axonal Charcot-MarieTooth disease, ${ }^{15}$ and Jokela type spinal muscular atrophy. ${ }^{16}$ All pathogenic $\mathrm{CHCHD} 10$ mutations are missense substitutions except for a stop-gain mutation (p.Q82X) suggesting a loss-offunction mechanism.

The collective understanding of $\mathrm{CHCHD} 10$ mutations in ALS began in $2014^{1}$ when a p.S59L mutation was identified in 8 affected members of a French family with autosomal dominant ALS/FTD using whole-exome sequencing. In 8 affected 


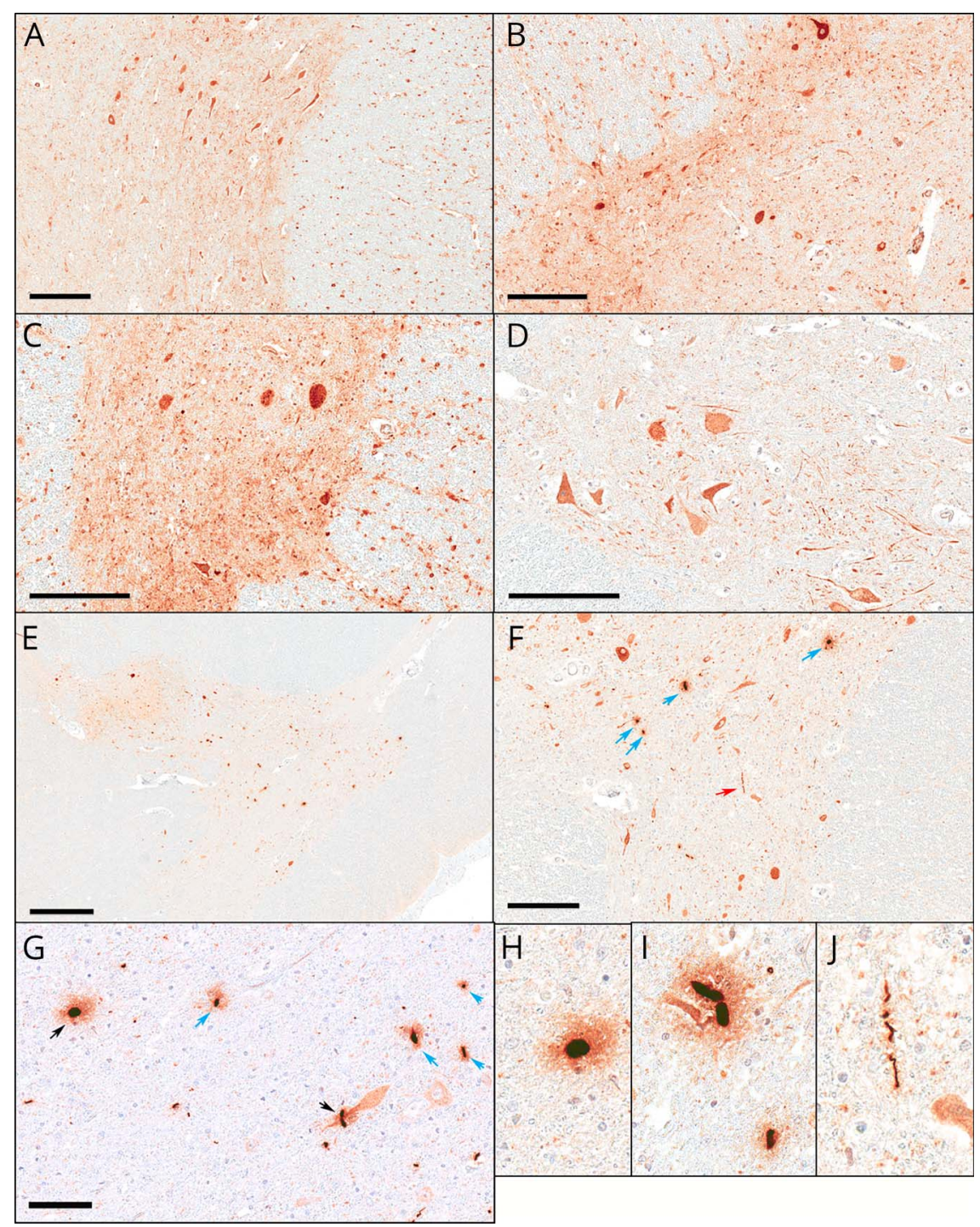

(A-C) CHCHD2 immunolabeling in the spinal cord of normal control (A), sporadic amyotrophic lateral sclerosis (ALS) (B), and CHCHD10 mutated ALS (C), all showing strong neuronal, glial, and endothelial cytoplasmic labeling in gray and white matter. (D) CHCHD10 immunolabeling in the normal control spinal cord showing strong neuronal, glial, and endothelial cytoplasmic labeling, which was comparable to sporadic ALS cases. (E-I) CHCHD10 immunolabeling of the spinal cord of CHCHD10 mutated ALS showing that in addition to the strong neuronal cytoplasmic labeling comparable to control cases and sporadic ALS cases, there are numerous aggregates of $\mathrm{CHCHD} 10$ within the anterior horn (arrows in $\mathrm{F}$ and $\mathrm{G}$. Aggregates indicated by black arrows in $\mathrm{G}$ are shown in $\mathrm{H}$ and I). There are also occasional corkscrew-shaped inclusions (red arrow in $\mathrm{F}$, higher magnification of this inclusion shown in J). Scale bar $=300 \mu \mathrm{m}(\mathrm{A}), 200 \mu \mathrm{m}$ (B-D, $\mathrm{F}$, and $\mathrm{G}), 500 \mu \mathrm{m}(\mathrm{E})$. members of a large French family with autosomal dominant frontotemporal dementia and/or amyotrophic lateral sclerosis2 (FTDALS2; 615903.0001), Bannwarth et al. ${ }^{1}$ identified a homozygous c.176C-T transition in exon 2 of the CHCHD10 gene, resulting in a ser59-to-leu (S59L) substitution at a highly conserved residue in the hydrophobic N-terminal alpha-helix. The mutation, which was found by whole-exome sequencing, segregated with the disorder in the family and was not present in the dbSNP (build 132), Exome Variant Server, or 1000 Genomes Project database, in in-house control exomes, or in 200 matched control alleles. The mutation, which was found by whole-exome sequencing, segregated with the disorder in the family and was not present in the dbSNP (build 132), Exome Variant Server, or 1000 Genomes Project database, in in-house control exomes, or in 200 matched control alleles. Genome sequencing of an ALS data set ${ }^{10}$ identified a large family segregating the p.R15L CHCHD10 substitution in 4 affected individuals, and the follow-up Sanger sequencing of
CHCHD10 in 84 patients with familial ALS found the same mutation in 2 more patients. All 6 patients carrying the p.R15L variant shared a $6.2 \mathrm{Mb}$ haplotype across the CHCHD10 gene $^{10,11}$ also reported the p.R15L mutation in 2 unrelated German ALS families with an autosomal dominant mode of inheritance but incomplete penetrance. The presence of unaffected p.R15L carriers among family members provoked discussion of whether p.R15L is truly pathogenic. ${ }^{17}$ However, segregation of p.R15L with disease could be masked by the complexity of $\mathrm{CHCHD10}$-related subphenotypes, late age at onset, and slow disease progression, as observed in our case. ${ }^{3,11}$ Recently, the MinE ALS consortium whole genome sequenced 4,365 patients with ALS and 1,832 controls $^{18}$ and reported that CHCHD10 mutations are less prevalent in pure ALS than originally suggested. They reported 3 new variants (1 ALS specific and 1 control specific), and there was no increased burden of $\mathrm{CHCHD} 10$ mutations among patients with ALS compared with controls. The few carriers with potentially 

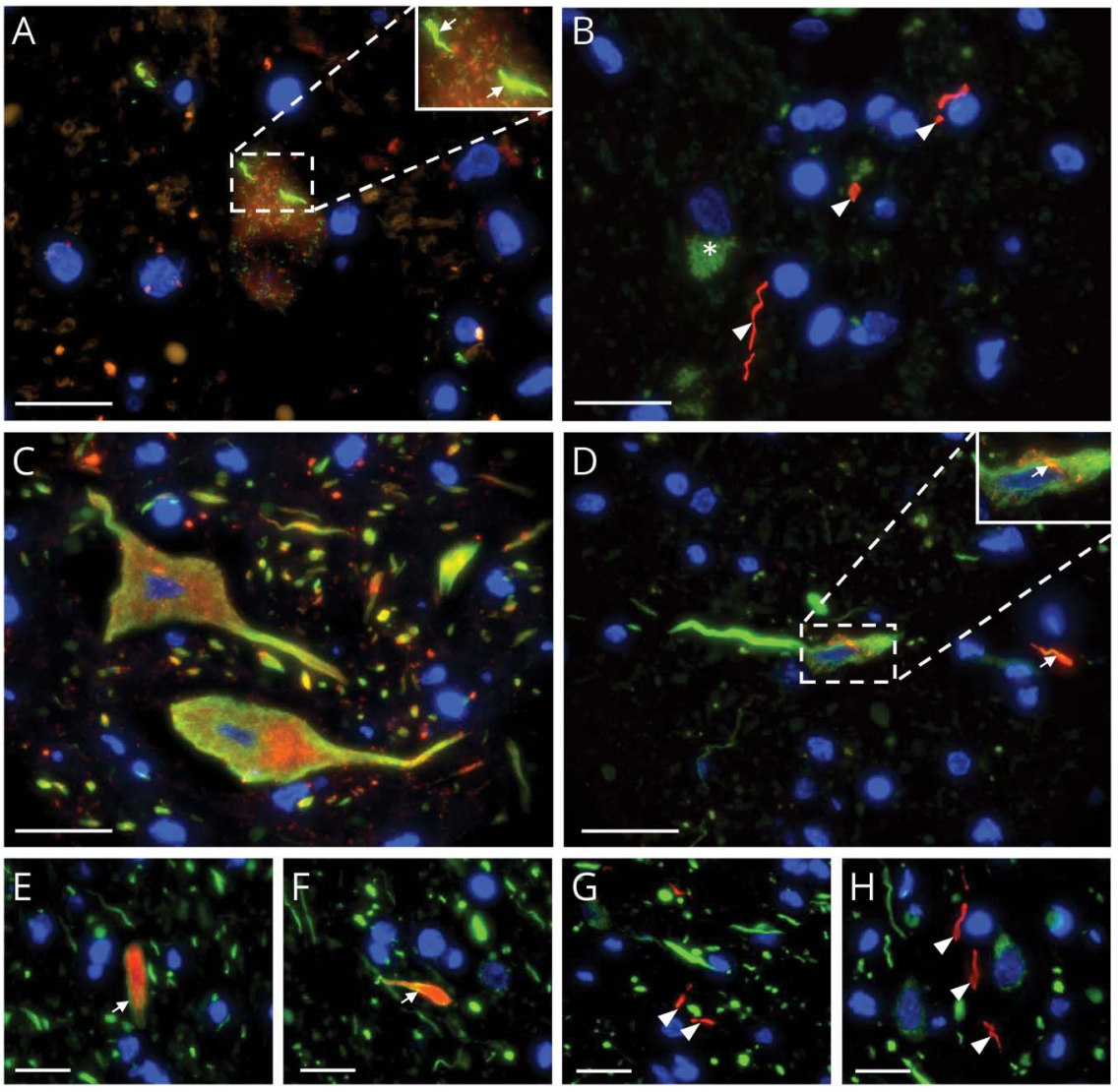

(A and B) Immunofluorescence overlay of CHCHD10 (red), phosphorylated TDP43 (green), and DAPI (blue) in the spinal cord of sporadic amyotrophic lateral sclerosis (ALS) (A) and CHCHD10 mutated ALS (B); arrows = TDP43 pathology; arrowheads = aggregated $\mathrm{CHCHD10;}$ asterisk = lipofuscin. $(\mathrm{C}-\mathrm{H})$ Overlay of $\mathrm{CHCHD} 10$ (red) and both nonphosphorylated/phosphorylated neurofilament $\mathrm{H}$ (NF-H; green) in normal control (C) and mutated CHCHD10 (D-H); arrows = aggregated $\mathrm{CHCHD} 10$ surrounded by NF-H; arrowheads $=$ extracellular CHCHD10 aggregates. Scale bar $=20 \mu \mathrm{m}$ ( $\mathrm{A}$ and $\mathrm{B}$ ); $30 \mu \mathrm{m}$ ( $\mathrm{C}$ and $\mathrm{D})$; and $10 \mu \mathrm{m}(\mathrm{E}-\mathrm{H})$. DAPI = 4',6-diamidino-2phenylindole.

pathogenic $\mathrm{CHCHD10}$ mutations exhibited a slowly progressive ALS-like phenotype with atypical features including myopathy and deafness.

Importantly, functional studies support the pathogenic role of the p.R15L mutation. The study of fibroblasts derived from the p.R15L carrier revealed a 2-fold reduction in CHCHD10, a 2.5fold increase in CHCHD2, a 2-fold decrease in complex I, a reduction in the amount of oxygen consumption, and an increase in anaerobic glycolysis when compared with a noncarrier. ${ }^{2}$ Furthermore, C. elegans deficient in har-1 (orthologue to human $\mathrm{CHCHD10}$ ) display locomotion abnormalities and reduced lifespan associated with mitochondrial superoxide overproduction, which were rescued by wild-type $\mathrm{CHCHD} 10$ but not $C H C H D 10$ with p.R15L or p.S59L mutations. ${ }^{19}$ In mammalian cells, overexpression of both $\mathrm{CHCHD} 10$ mutations exhibited abnormal mitochondrial phenotypes and reduced pre/postsynaptic integrity. ${ }^{19}$ Finally, the pathogenic nature of p.R15L is further supported by its absence in the Healthy Exomes database that contains sequencing results from $\sim 500$ controls older than 60 years who had no neurodegenerative neuropathology (alzforum.org/exomes/hex).

By what mechanism could a $\mathrm{CHCHD} 10$ mutation induce an ALS phenotype? Mitochondrial dysfunction and oxidative stress are known to contribute to neurodegeneration and cellular aging, ${ }^{20}$ and pathogenic mitochondria-related proteins have been identified in many neurodegenerative conditions. $^{20,21}$ The discovery of mutations in CHCHD1O has lent support to the long-suspected role of mitochondrial dysfunction in the pathogenesis of ALS; previously, there have been few reported mutations in genes encoding bona fide mitochondrial proteins in the context of ALS. Intriguingly, several lines of evidence suggest a functional link between CHCHD10 and TDP43. For instance, the neurotoxicity of TDP43 may be mediated by mitochondrial dysfunction ${ }^{22-24}$; the role of mitochondrial dysfunction, morphology, fission/fusion dynamics, distribution, and trafficking in ALS has been reviewed. ${ }^{25}$ Recent cell culture and animal model studies have shown that TDP43 interacts with CHCHD10 and promotes its nuclear localization. ${ }^{19}$ Specifically, CHCHD10 mutations (p.R15L and p.S59L) exhibit dominant negative activities in mammalian systems, resulting in mitochondrial/synaptic damage and cytoplasmic TDP43 accumulation. A recent fibroblast culture study demonstrated that the cellular phenotypes of specific CHCHD10 mutations differ and that loss of MICOS complex integrity and mitochondrial dysfunction, but not TDP43 mitochondrial localization, may be required to develop a severe motor neuron disease phenotype. ${ }^{26}$ 
The present report is a neuropathologic description of a rare ALS case with a pathogenic $C H C H D 10$ mutation. We have observed in the present case some of the classic histopathologic findings of ALS, namely severe loss of lower motor neurons of the spinal cord and hypoglossal nucleus and mild corticospinal tract degeneration. The burden of our patient's disease being primarily lower motor neuron and in the cervical spinal cord correlates well with his clinical symptoms including arm weakness at onset followed by the development of lower motor neuron signs in the bulbar and cervical, thoracic, and lumbosacral segments and upper motor neuron signs in the bulbar and lumbosacral regions. The absence of coexisting FTLD correlates well with his intact cognition and absent behavioral symptoms. Some of the observed pathology in our case is somewhat unexpected, including the lack of TDP43 motor neuron immunopathology, given both the presence of TDP43 immunopathology in the vast majority of ALS cases and the suggested functional links between CHCHD10 and TDP43. Double immunofluorescence labeling clearly showed that the observed $\mathrm{CHCHD} 10$ aggregates did not colocalize with TDP43. The absence of Lewy body pathology, nigral degeneration, and cerebellar pathology is pertinent, given the previous descriptions of parkinsonism and ataxia in the presence of $\mathrm{CHCHD} 10$ mutations, and our case showed neither the focal "ischemic-like" lesions nor diffuse neuronal or white matter loss that has been described in the CNS of patients with mitochondriopathies.

The literature contains minimal information about the pattern of $\mathrm{CHCHD} 2$ and $\mathrm{CHCHD} 10$ immunostaining within the human nervous system in its normal state or in the setting of neurodegenerative disease such as ALS. According to the Human Protein Atlas (proteinatlas.org/ENSG00000250479CHCHD10/antibody\#immunocytochemistry), the distribution of CHCHD10 immunohistochemical staining is consistent with RNA expression levels across 36 tissues. There is a recent description of a Parkinson disease case, Lewy body dementia case, and ALS/FTD case in which CHCHD2 and CHCHD10 immunostaining showed strong neuronal staining in the substantia nigra and cortex and hippocampus, respectively; the authors suggest that $\mathrm{CHCHD} 2$ and $\mathrm{CHCHD} 10$ are highly coexpressed in the affected cell types in these conditions. $^{27}$

Animal models have shown CHCHD10 to be highly expressed in the motor neurons of the spinal cord, and both knock-out and knock-in $\mathrm{CHCHD} 10$ mutant mouse models have been created. ${ }^{28} \mathrm{CHCHD} 10^{S 55 L}$ knock-in mice, which mimic the human p.S59L mutation, exhibit late-onset progressive motor deficits and early mortality. These mice have been shown to house aggregates of $\mathrm{CHCHD} 10$ and $\mathrm{CHCHD} 2$ in their affected tissues, including the spinal cord, by filter trap assay. These aggregates trigger a mitochondrial integrated stress response and may be linked to mitochondrial degeneration and disease in a tissue selective fashion. ${ }^{28}$ The aggregates of CHCHD10 seen in our patient's anterior horns could represent a histologic correlate of the
CHCHD10 aggregates described in the CHCHD $10^{855 \mathrm{~L}}$ mouse model; however, our patient's $\mathrm{CHCHD} 10$ mutation was a loss of function p.R15L mutation. The mouse model did not have anterior horn motor neuron loss leading to speculation that the motor symptoms in the setting of a $\mathrm{CHCHD} 10$ mutation may result from motor peripheral neuropathy. ${ }^{28}$ Our findings dispute this suggestion, as our patient had severe loss of anterior horn and hypoglossal motor neurons.

The cellular location of the CHCHD10 aggregates we describe on immunohistochemistry and immunofluorescence is interesting; the fact that occasional aggregates are surrounded by NF may suggest that these aggregates are originally developing within neuronal cell processes. The vast majority of $\mathrm{CHCHD} 10$ aggregates were not surrounded by $\mathrm{NF}$, however, which may indicate that after the death of the parent neuron, the remaining aggregates have an extracellular location.

Overall, this study describes the neuropathology and unique CHCHD10 immunostaining pattern in a patient with ALS due to $C H C H D 10$ p.R15L mutation and sheds further light on recently reported findings from an animal model.

\section{Study funding}

This work in part was supported by the Canadian Consortium on Neurodegeneration in Aging (E. Rogaeva and M. Zhang), the ALS Canada-Brain Canada Hudson Grant (J. Robertson, E. Rogaeva, and L. Zinman), and the James Hunter ALS Initiative (J. Robertson and L. Zinman).

\section{Disclosure}

J.L. Keith, E. Swinkin, A. Gao, S. Alminawi, M. Zhang, P. McGoldrick, P. McKeever, J. Robertson, E. Rogaeva, and L. Zinman report no disclosures. Go to Neurology.org/NG for full disclosure.

\section{Publication history}

Received by Neurology: Genetics February 13, 2019. Accepted in final form November 22, 2019.

Appendix Authors

\begin{tabular}{|c|c|c|c|}
\hline Name & Location & Role & Contribution \\
\hline $\begin{array}{l}\text { Julia L. } \\
\text { Keith, MD }\end{array}$ & $\begin{array}{l}\text { Sunnybrook Health } \\
\text { Sciences Centre, } \\
\text { Toronto }\end{array}$ & Author & $\begin{array}{l}\text { Designed and } \\
\text { executed } \\
\text { neuropathology } \\
\text { methods, } \\
\text { neuropathology data } \\
\text { collection, generated } \\
\text { most figures, } \\
\text { supervised trainees, } \\
\text { reviewed the } \\
\text { literature, and wrote } \\
\text { and submitted the } \\
\text { manuscript }\end{array}$ \\
\hline
\end{tabular}


Appendix (continued)

\begin{tabular}{|c|c|c|c|}
\hline Name & Location & Role & Contribution \\
\hline $\begin{array}{l}\text { Emily } \\
\text { Swinkin, MD }\end{array}$ & $\begin{array}{l}\text { Sunnybrook Health } \\
\text { Sciences Centre, } \\
\text { Toronto }\end{array}$ & Author & $\begin{array}{l}\text { Reviewed and } \\
\text { summarized clinical } \\
\text { records and } \\
\text { contributed to } \\
\text { manuscript writing and } \\
\text { review }\end{array}$ \\
\hline
\end{tabular}

\begin{tabular}{|c|c|c|c|}
\hline $\begin{array}{l}\text { Andrew } \\
\text { Gao, MD }\end{array}$ & $\begin{array}{l}\text { Sunnybrook Health } \\
\text { Sciences Centre, } \\
\text { Toronto }\end{array}$ & Author & $\begin{array}{l}\text { Neuropathology data } \\
\text { collection and } \\
\text { contributed to } \\
\text { manuscript writing and } \\
\text { review }\end{array}$ \\
\hline $\begin{array}{l}\text { Samira } \\
\text { Alminawi, } \\
\text { MLT }\end{array}$ & $\begin{array}{l}\text { Sunnybrook Health } \\
\text { Sciences Centre, } \\
\text { Toronto }\end{array}$ & Author & $\begin{array}{l}\text { Validated and } \\
\text { conducted } \\
\text { immunohistochemical } \\
\text { portion of } \\
\text { neuropathology } \\
\text { methods }\end{array}$ \\
\hline
\end{tabular}

Ming Zhang, Tongji University, Author Executed molecular

PhD Zhang, Tongji University, Author Executed mol

\begin{tabular}{|c|c|c|}
\hline Ond & Snangnal, cnina & methods \\
\hline
\end{tabular}

McGoldrick, Research in Author methods

PhD Neurodegenerative

Diseases, Toronto

\begin{tabular}{llll}
\hline $\begin{array}{l}\text { Paul } \\
\text { McKeever, }\end{array}$ & $\begin{array}{l}\text { Tanz Centre for } \\
\text { Research in }\end{array}$ & Author & $\begin{array}{l}\text { Conducted } \\
\text { immunofluorescence }\end{array}$
\end{tabular}

PhD Neurodegenerative methods and image

Diseases, Toronto acquisition,

contributed to

manuscript writing and

review, and executed

molecular methods

\begin{tabular}{|c|c|c|c|}
\hline $\begin{array}{l}\text { Janice } \\
\text { Robertson, } \\
\text { PhD }\end{array}$ & $\begin{array}{l}\text { Tanz Centre for } \\
\text { Research in } \\
\text { Neurodegenerative } \\
\text { Diseases, Toronto }\end{array}$ & Author & $\begin{array}{l}\text { Conducted } \\
\text { immunofluorescence } \\
\text { studies, literature } \\
\text { review, and } \\
\text { contributed to } \\
\text { manuscript writing and } \\
\text { review }\end{array}$ \\
\hline
\end{tabular}

\begin{tabular}{lll}
\hline $\begin{array}{l}\text { Ekaterina } \\
\text { Rogaeva, }\end{array}$ & Tanz Centre for & Author \\
PhD & Nesearch in & $\begin{array}{l}\text { Contributed to project } \\
\text { design, executed } \\
\text { molecular methods, } \\
\text { Diseases, Toronto }\end{array}$ \\
& & $\begin{array}{l}\text { reviewed the } \\
\text { molecular literature, } \\
\text { generated some } \\
\text { figures, and } \\
\text { contributed to the } \\
\text { manuscript writing and } \\
\text { review }\end{array}$ \\
\hline
\end{tabular}

\begin{tabular}{lll}
\hline Lorne & $\begin{array}{l}\text { Sunnybrook Health } \\
\text { Zinman, MD }\end{array}$ & Author \\
Toronto & & $\begin{array}{l}\text { Primary physician for } \\
\text { the patient, provided } \\
\text { clinical data, and } \\
\text { contributed to the } \\
\text { manuscript writing and } \\
\text { review }\end{array}$ \\
& &
\end{tabular}

\section{References}

1. Bannwarth S, Ait-El-Mkadem S, Chaussenot A, et al. A mitochondrial origin for frontotemporal dementia and amyotrophic lateral sclerosis through CHCHD10 involvement. Brain 2014;137:2329-2345.
2. Straub IR, Janer A, Weraarpachai W, et al. Loss of CHCHD10-CHCHD2 complexes required for respiration underlies the pathogenicity of a CHCHD10 mutation in ALS. Hum Mol Genet 2018;27:178-189.

3. Zhang M, Xi Z, Zinman L, et al. Mutation analysis of CHCHD10 in different neurodegenerative diseases. Brain 2015;138:e380.

4. Ghani M, Lang AE, Zinman L, et al. Mutation analysis of patients with neurodegenerative disorders using NeuroX array. Neurobiol Aging 2015;36:545.e9-545.e14.

5. Brooks RB, Miller RG, Swash M, Munsat TL; World Federation of Neurology Research Group on Motor Neuron Diseases. El Escorial revisited: revised criteria for the diagnosis of amyotrophic lateral sclerosis. Amyotroph Lateral Scler Other Motor Neuron Disord 2000;1:293-299.

6. Ajroud-Driss S, Fecto F, Ajroud K, et al. Mutation in the novel nuclear-encoded mitochondrial protein CHCHD10 in a family with autosomal dominant mitochondrial myopathy. Neurogenetics 2015;16:1-9.

7. Genin EC, Plutino M, Bannwarth S, et al. CHCHD10 mutations promote loss of mitochondrial cristae junctions with impaired mitochondrial genome maintenance and inhibition of apoptosis. EMBO Mol Med 2016;8:58-72.

8. Purandare N, Somayajulu M, Hüttemann M, Grossman LI, Aras S. The cellular stress proteins CHCHD10 and MNRR1 (CHCHD2): partners in mitochondrial and nuclear function and dysfunction. J Biol Chem 2018;293:6517-6529.

9. Chaussenot A, Le Ber I, Ait-El-Mkadem S, et al. Screening of CHCHD10 in a French cohort confirms the involvement of this gene in frontotemporal dementia with amyotrophic lateral sclerosis patients. Neurobiol Aging 2014;35:2884.e1-2884.e4.

10. Johnson JO, Glynn SM, Gibbs JR, et al. Mutations in the CHCHD10 gene are a common cause of familial amyotrophic lateral sclerosis. Brain 2014;137:e311.

11. Müller K, Andersen PM, Hübers A, et al. Two novel mutations in conserved codons indicate that $\mathrm{CHCHD} 10$ is a gene associated with motor neuron disease. Brain 2014; 137:e309.

12. Rubino E, Zhang M, Mongini $\mathrm{T}$, et al. Mutation analysis of $\mathrm{CHCHD} 2$ and CHCHD10 in Italian patients with mitochondrial myopathy. Neurobiol Aging 2018; 66:181.e1-181.e2.

13. Ait-El-Mkadem S, Chaussenot A, Bannwarth S, Rouzier C, Paquis-Flucklinger V. CHCHD10-related disorders. In: Adam MP, Ardinger HH, Pagon RA, Wallace SE, Bean LJH, Stephens K, Amemiya A, editors. GeneReviews ${ }^{\circledR}$ [Internet]. Seattle, WA: University of Washington; 1993-2019.

14. Zhou X, Liu Z, Guo J, et al. Identification of CHCHD10 variants in Chinese patients with Parkinson's disease. Parkinsonism Relat Disord 2018;47:96-97.

15. Auranen M, Ylikallio E, Shcherbii M, et al. CHCHD10 variant p.(Gly66Val) causes axonal Charcot-Marie-Tooth disease. Neurol Genet 2015;1:e1.

16. Penttilä S, Jokela M, Bouquin H, Saukkonen AM, Toivanen J, Udd B. Late onset spinal motor neuronopathy is caused by mutation in CHCHD10. Ann Neurol 2015;77: $163-172$.

17. van Rheenen W, Diekstra FP, van den Berg LH, Veldink JH. Are CHCHD10 mutations indeed associated with familial amyotrophic lateral sclerosis? Brain 2014;137:e313.

18. Tazelaar GHP, van Rheenen W, Pulit SL, et al; Project MinE ALS Sequencing Consortium. CHCHD10 variants in amyotrophic lateral sclerosis: where is the evidence? Ann Neurol 2018;84:110-116.

19. Woo JA, Liu T, Trotter C, et al. Loss of function CHCHD10 mutations in cytoplasmic TDP-43 accumulation and synaptic integrity. Nat Commun 2017;8:15558.

20. Lin MT, Beal MF. Mitochondrial dysfunction and oxidative stress in neurodegenerative diseases. Nature 2006;443:787-795.

21. Duffy LM, Chapman AL, Shaw PJ, Grierson AJ. Review: the role of mitochondria in the pathogenesis of amyotrophic lateral sclerosis. Neuropathol Appl Neurobiol 2011; 37:336-352.

22. Wang W, Li L, Lin WL, et al. The ALS disease-associated mutant TDP43 impairs mitochondrial dynamics and function in motor neurons. Hum Mol Genet 2013;22: 4706-4719.

23. Wang W, Wang L, Lu J, et al. The inhibition of TDP43 mitochondrial localization blocks its neuronal toxicity. Nat Med 2016;22:869-878.

24. Xu YF, Gendron TF, Zhang YJ, et al. Wild-type human TDP43 expression causes TDP43 phosphorylation, mitochondrial aggregation, motor deficits, and early mortality in transgenic mice. J Neurosci 2010;30:10851-10859.

25. Jiang Z, Wang W, Perry G, Zhu X, Wang X. Mitochondrial dynamic abnormalities in amyotrophic lateral sclerosis. Transl Neurodegen 2015;4:14-20.

26. Genin EC, Bannwarth S, Lespinasse F, et al. Loss of MICOS complex integrity and mitochondrial damage, but not TDP-43 mitochondrial localisation, are likely associated with severity of CHCHD10-related diseases. Neurobiol Dis 2018;119: 159-171.

27. Huang X, Wu BP, Nguyen D, et al. CHCHD2 accumulates in distressed mitochondria and facilitates oligomerization of CHCHD10. Hum Mol Genet 2018;27: 3881-3900.

28. Anderson CJ, Bredvik K, Burstein SR, et al. ALS/FTD mutant CHCHD10 mice reveal a tissue-specific toxic gain-of-function and mitochondrial stress response. Acta Neuropathol 2019;138:103-121. 


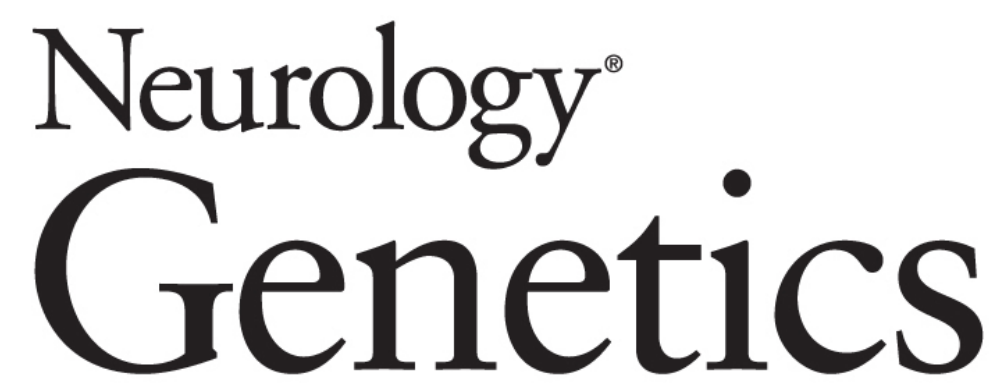

Neuropathologic description of $\mathrm{CHCHD10}$ mutated amyotrophic lateral sclerosis Julia L. Keith, Emily Swinkin, Andrew Gao, et al. Neurol Genet 2020;6;

DOI 10.1212/NXG.0000000000000394

This information is current as of January 13, 2020

Neurol Genet is an official journal of the American Academy of Neurology. Published since April 2015, it is an open-access, online-only, continuous publication journal. Copyright Copyright $\odot 2020$ The Author(s). Published by Wolters Kluwer Health, Inc. on behalf of the American Academy of Neurology.. All rights reserved. Online ISSN: 2376-7839.

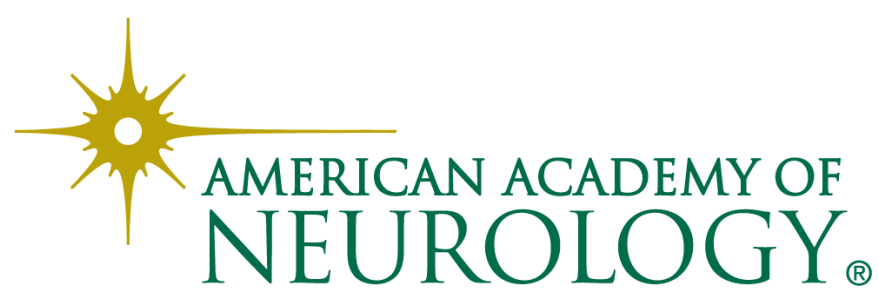




\section{Updated Information \& Services}

References

Citations

Subspecialty Collections

Permissions \& Licensing

Reprints including high resolution figures, can be found at: http://ng.neurology.org/content/6/1/e394.full.html

This article cites 27 articles, 4 of which you can access for free at: http://ng.neurology.org/content/6/1/e394.full.html\#\#ref-list-1

This article has been cited by 3 HighWire-hosted articles: http://ng.neurology.org/content/6/1/e394.full.html\#\#otherarticles

This article, along with others on similar topics, appears in the following collection(s):

\section{All Genetics}

http://ng.neurology.org//cgi/collection/all_genetics

All Neuromuscular Disease

http://ng.neurology.org//cgi/collection/all_neuromuscular_disease Amyotrophic lateral sclerosis

http://ng.neurology.org//cgi/collection/amyotrophic_lateral_sclerosis_ Anterior nerve cell disease

http://ng.neurology.org//cgi/collection/anterior_nerve_cell_disease Mitochondrial disorders

http://ng.neurology.org//cgi/collection/mitochondrial_disorders

Information about reproducing this article in parts (figures,tables) or in its entirety can be found online at:

http://ng.neurology.org/misc/about.xhtml\#permissions

Information about ordering reprints can be found online:

http://ng.neurology.org/misc/addir.xhtml\#reprintsus

Neurol Genet is an official journal of the American Academy of Neurology. Published since April 2015, it is an open-access, online-only, continuous publication journal. Copyright Copyright $\odot 2020$ The Author(s). Published by Wolters Kluwer Health, Inc. on behalf of the American Academy of Neurology.. All rights reserved. Online ISSN: 2376-7839.

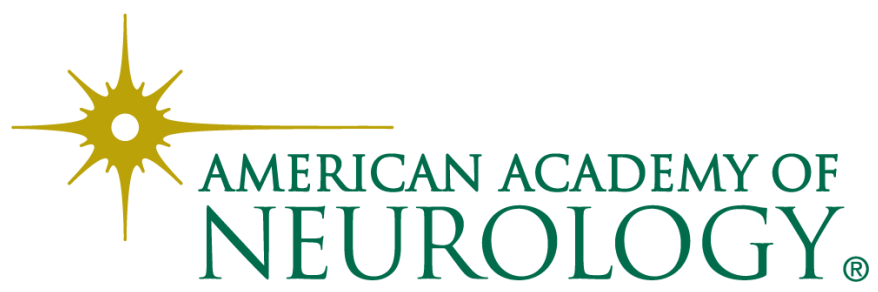

